\title{
Artificial Immune-based Algorithm for Academic Leadership Assessment
}

\author{
Hamidah Jantan ${ }^{1}$, Nur Hamizah Syafiqah Che Azemi ${ }^{2}$ \\ Faculty of Computer and Mathematical Sciences \\ Universiti Teknologi MARA (UiTM) Terengganu \\ Kuala Terengganu, Terengganu \\ Malaysia
}

\author{
Zulaiha Ali Othman ${ }^{3}$ \\ Center of Artificial Intelligence Technology \\ Faculty of Information Science and Technology \\ Univsersiti Kebangsaan Malaysia \\ Bangi, Selangor, Malaysia
}

\begin{abstract}
Artificial Immune-based algorithm is inspired by the biological immune system as computational intelligence approach in data analysis. Negative selection algorithm is derived from immune-based algorithm's family that used to recognize the pattern's changes perform by the gene detectors in complementary state. Due to the self-recognition ability, this algorithm is widely used to recognize the abnormal data or nonself especially for fault diagnosis, pattern recognition, network security etc. In this study, the self-recognition performance proposed by the negative selection algorithm been considered as a potential technique in classifying employee's competency. Assessing the employee's performance in organization is an important task for human resource management people to identify the right candidate in job promotion assessment. Thus, this study attempts to propose an immune-based model in assessing academic leadership performance. There are three phases involved in experimental phase i.e. data acquisition and preparation; model development; and analysis and evaluation. The data consists of academic leadership proficiency was prepared as data-set for learning and detection processes. Several experiments were conducted using cross validation process on different model to identify the most accurate model. Therefore, the accuracy of NS classifier is considered acceptable enough for this academic leadership assessment case study. For enhancement, other immune-based algorithm or bio-inspired algorithms, such as genetic algorithm, particle swam optimization, ant colony optimization would also be considered as a potential algorithm for performance assessment.
\end{abstract}

Keywords-Immune-based algorithm; negative selection algorithm; academic leadership; performance assessment

\section{INTRODUCTION}

In biological immune system, the learning process is through the evolution of distinguishing between our body's own cell and foreign antigen. This immune system behavior proposed a new paradigm in computational intelligence for data analysis [1]. Negative selection algorithm in Artificial Immune System (AIS) technique uses immunological principle by recognizing and categorizing the self on non-self in complementary basis for all body cells. The first negative selection algorithm was introduced by Forrest to identify information affected by the biological based infection and that was transformed to machine learning context [2]. This algorithm is mainly used to detect changes of pattern's behavior in complementary space performed by the gene detectors. The detectors are used to classify the new data

This study is funded by Fundamental Re-search Grant Scheme (FRGS) (600-RMI/FRGS 5/3 (3/2016). whether it is self (normal) or non-self (ab-normal). This algorithm mostly used for anomaly detection by classifying the self and non-self's detectors such as in computer virus detection, network intrusion detection, fault diagnose, network security and many others area [3]. Besides that negative selection algorithm can also be used in pattern recognition area by matching the self or non-self's detectors in classifying the pattern.

The process of talent assessment in HR field involves highly on human decisions by managing employee's advancement through promotion exercises, those tasks are very subjective, uncertain and difficult [4]. In HR field, employee's assessment process is a way for an employee to enhance his/her career path development. This process can be implemented by using various approaches and it also depends on the employee's competency criteria based on their job specification. In higher learning institution, academic leadership competency refers to academic leadership ability such as in teaching and supervision, research and publication, expertise and contribution to university or society etc.

Due to the ability of Negative selection algorithm for classification in previous studies [1-3], this paper attempts to apply this algorithm for talent assessment as part of talent management task in Human Resource (HR) field by classifying the selected criteria for leadership assessment. In this study, negative selection algorithm is used as a potential method in assessing an employee for promotion based on biological immune system behavior. The paper is organized as follows. Section 2 describes immune-based algorithm, negative selection algorithm and academic leadership in higher learning institution. Section 3 explains the research method and Section 4 discusses on result of the experiments. Section 5 presents the conclusion and future directions for academic leadership assessment using immune-based system approach.

\section{RELATED WORK}

\section{A. Artificial Immune-Based Algorithm}

Immune-based algorithm in computational intelligence using immunological principles inspired by biological immune system in the living organism for data analysis and known as Artificial Immune System (AIS) algorithms [1]. These algorithms are proposed from behavior of various types of natural immune systems. Clonal Se-lection Algorithm, Immune Networks Algorithm, Negative Selection Algorithm and 
Dendritic Cell Algorithm are among the algorithms that derived from AIS algorithm's family [5]. As an example, negative selection algorithm using immunological principle by recognizing cells within the body and categorize those cells as self on non-self in complementary basis which is this approach can be used to categorize or classify the important element in data analysis [3].

\section{B. Negative Selection Algorithm}

The Negative Selection (NS) algorithm is inspired by discrimination of the self and non-self through behavior observed in the mammalian learned in their immune system as shown in Fig. 1. Negative selection aims to provide tolerance for self-cells that deals with immune system's ability to detect unknown antigens while not re-acting to the self-cell. In biological immune system process for T-cell maturation, if a Tcell in thymus recognized any self-cell, it is eliminated, and then immune functionality is performed [2]. The NS behavior in natural immune system was gives a new direction for other Artificial Immune System (AIS) algorithms development.

This scenario has similarity with artificial immune system technique where the NS algorithm generates detector set by eliminating any detector candidate that matches with elements from a group of self-samples [5]. The job of T-cells will be performed by the population of detectors that is represented in the fixed length binary strings. A simple rule is used to compare bits in two such strings that has been selected from the population of detectors to check whether matching has occurred or not. This matching process is similar with natural mammals' immune system in matching between a lymphocyte and antigen. A sample of unlabelled data from certain area of problem domain will be trained to generate the set of detectors. Then, this detector will used to determine whether exist any new hidden data points belonging to the same sub-area or not.

NS algorithm uses the same principal where the detector has ability to recognise the pattern in small sub-area of the problem. This algorithm consists of two main steps as shown in Fig. 2. The first step is to generate a set of detectors to represent the unmatched string comparing with a predetermined substring as a memory cell. The string-matching rule usually applied on partial of the string, because it can be extremely rare that the generated random strings exactly match with the predetermined substring, even though the strings are small. There are several matching-rules that can be used in matching process as affinity measurement and it also depends on the data representation. For real data representation, RContiguous, R-chunk, Hamming Distance, Hamming-shapespace are commonly used matching-rule for matching process. The string data representation usually uses Euclidean Distance, Manhattan Distance and Makowski Distance. Next, the second step for NS algorithm is to perform comparing process between new data and the detector. If a detector recognized a change has occurred in string pattern, this will demonstrate the anomaly state exists in original data [6-7]. This approach might look simple and easy to execute, but it is an effective method especially when dealing with a small set of detectors strings as it will produce very high probability of recognizing the changes in the existing data.

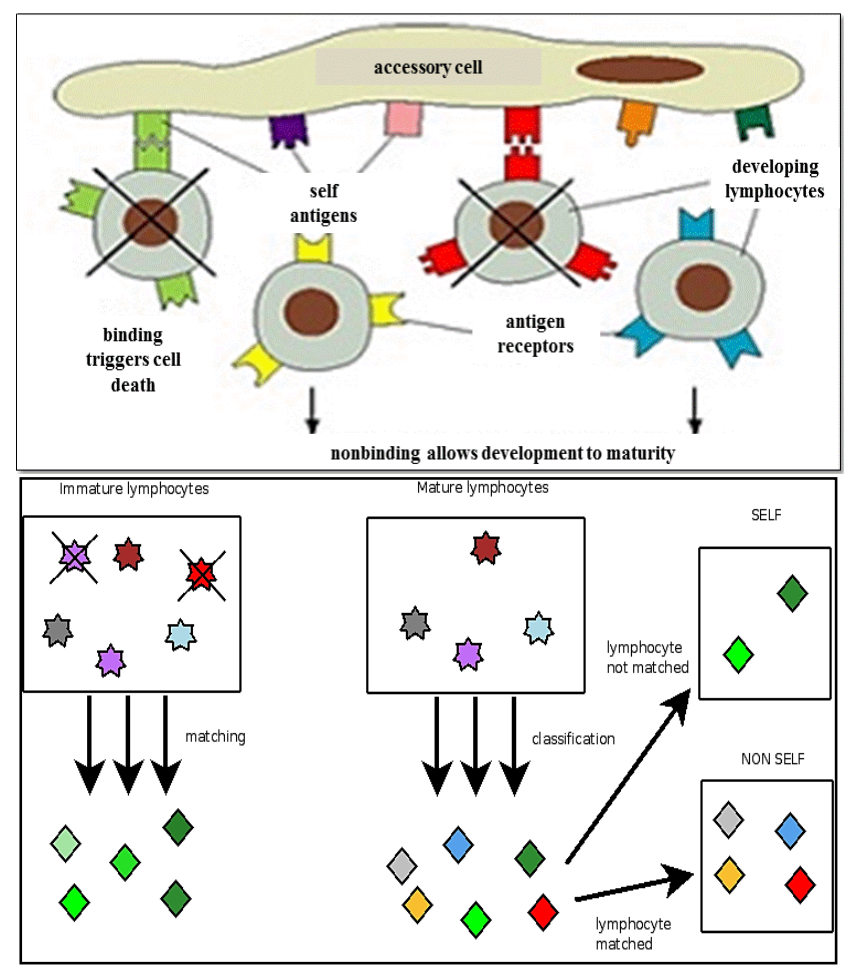

Fig. 1. Negative Selection Process in Vertebrate Immune System.

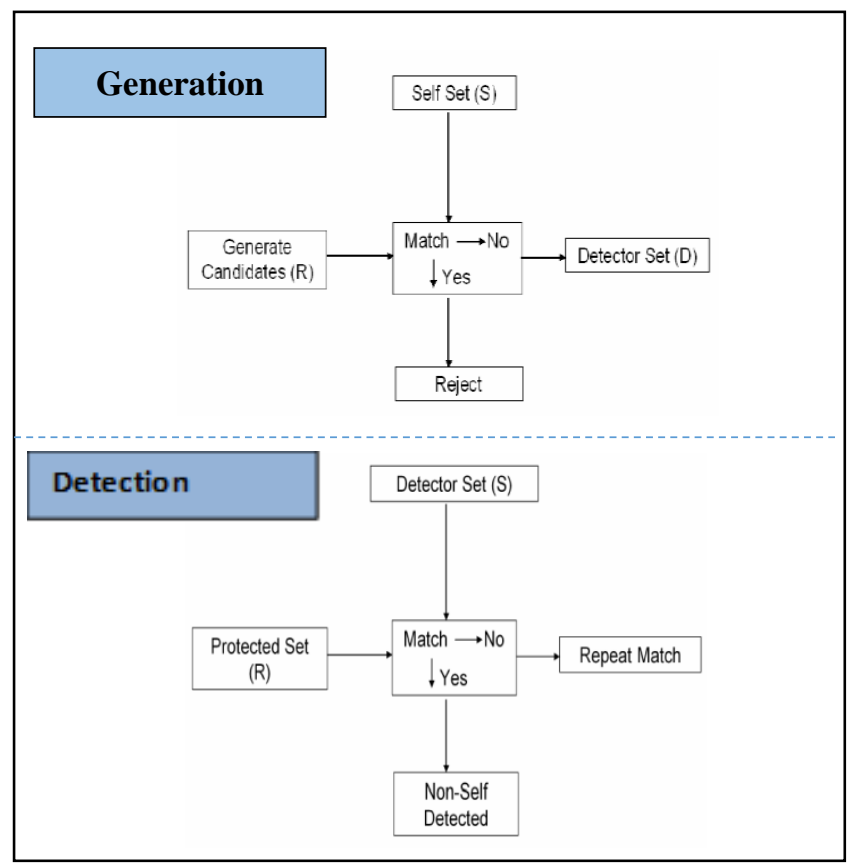

Fig. 2. Fundamental of Negative Selection Algorithm.

Recently, there are many areas applied NS algorithm to solve their problem and mainly it used anomaly detection by classifying self or non-self as detectors such as in computer virus detection, network security, network intrusion detection, fault diagnose, pattern recognition, business, etc. Table I shows several examples of application for specific purpose using negative selection algorithm technique for solving their problems [3]. 
TABLE. I. NEGATIVE SELECTION ALGORITHM APPLICATIONS

\begin{tabular}{|l|l|}
\hline Application Area & Issues/Problem domain \\
\hline Fault Diagnose & $\begin{array}{l}\text { Aircraft Fault Detection [8] } \\
\text { Disturbance Detection for Optimal Database Storage } \\
\text { in Electrical Distribution Systems [9] } \\
\text { Spam Detection [10] } \\
\text { Fault Detection in Refrigeration Systems [11] }\end{array}$ \\
\hline $\begin{array}{l}\text { Network Security } \\
\text { Detection }\end{array}$ & $\begin{array}{l}\text { Network Intrusion Detection [12] } \\
\text { Traffic Intrusion Detection [13] }\end{array}$ \\
\hline Pattern Recognition & $\begin{array}{l}\text { Image classification [14] } \\
\text { Music Feature Recognition [15] }\end{array}$ \\
\hline $\begin{array}{l}\text { Classification / } \\
\text { Selection }\end{array}$ & $\begin{array}{l}\text { Merger and Acquisition Target Identification [16] } \\
\text { Patient classification [17] }\end{array}$ \\
\hline
\end{tabular}

\section{Academic Leadership Assessment in Higher Learning Institution}

In higher learning institution, activities such as teaching, supervision, research, publication, service to university and service to the society are among the academic duties. These duties play an important role as competency measurement in managing academic leadership development [18]. Nevertheless, the emphasis and scope of these duties also depends on other factors such as university's direction, seniority and specialization, and academic appointment [19]. As an academia, teaching and supervising is about educating students in the specific field of study. In many cases, they also need to enhance their understanding especially when it involve with technology advancement. Besides that, they also must do academic research which is it can be extreme, inspiring, and worthwhile.

Academic research involves numerous exercises such as getting funding, knowledge sharing, knowledge transfer and many others besides exploring new discoveries in their field. They must spend their time in comprising for financing their research by preparing a good research proposal to attract interest from grant provider. In academic research, proposing experimental paper to reporting research discoveries and presenting this finding in any scientific conferences play an important role towards body of knowledge contribution. As researcher, there are enormous tasks that need to be carried out and experiment to conduct. Nevertheless, most of re-searchers are committed, patience and hard work in their duties since they love to do that [20]. In evaluating the competency of academic leadership in higher learning institution, all these aspects should be taken into consideration. Several individual factors that can be mapped with academic leadership context to produce academic leadership talent are shown in Fig. 3.

Nowadays, academic talent marketplace is highly competitive to determine the current and future direction for higher learning institution [21]. Academic talent is recognized by assessing academic leadership abilities that are needed to ensure the development of excellence in education-based institution. Academic leadership is an 'intellectual leadership' that focuses on the development of leading ideas and the establishment of new academic directions by giving the narrow and compartmentalized forms of knowledge as an academia. A higher learning institution needs to be able to identify the potential academic talent to ensure the competitive advantage for the institution will be achieved. The issues that associated with recruitment and retirement of academic talent is considered as the key of long-term success and competitiveness in higher learning institution. Hence, this study attempts to apply the Immune-based algorithm as an approach to classify the academic talent through academic leadership criterion. There are several researches had been conducted on this issue using soft computing and data mining techniques and they are proven successful [22, 23]. However, the evolutionary computation and bio-inspired algorithm such as Genetic Algorithm, Ant Colony Optimization and Artificial Immune System (AIS) has not attracted researchers in this area.

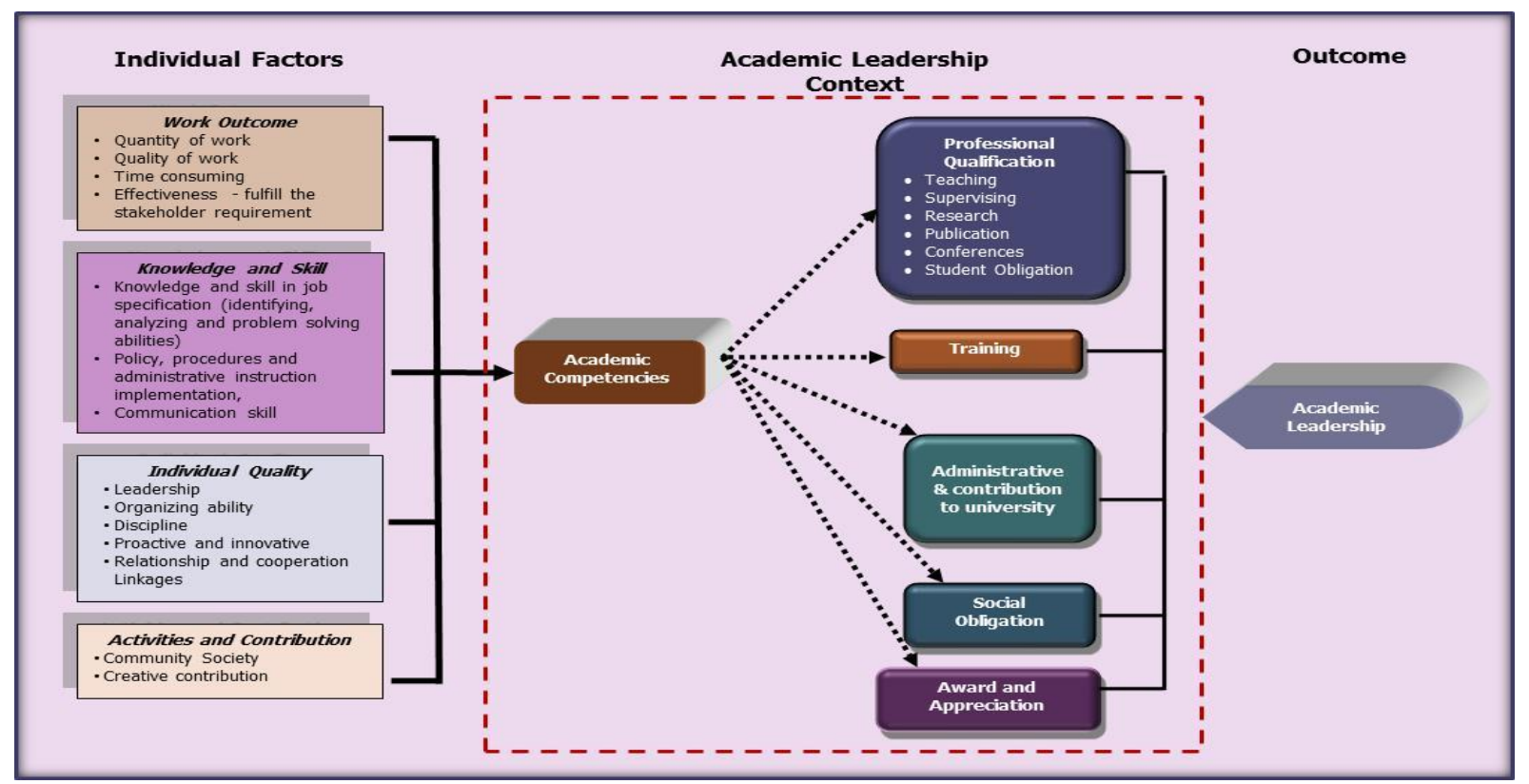

Fig. 3. Academic Leadership Mapping Criteria in Higher Learning. 


\section{RESEARCH METHOD}

The experiment was conducted on NS algorithm as selected algorithm from immune-based algorithm as a case study in academic leadership assessment. The data was collected based on academic leadership criteria used in academic promotion evaluation. There are three phases involved in experimental phase i.e. data acquisition and preparation; model development; and analysis and evaluation as shown in Table II. The gathering information and data acquisition in the first phase focus on preparing the datasets for training process. The data was obtained from academic promotion evaluation results as sample of dataset. The selected attributes of this dataset are demographic and the evaluation assessment result from academic promotion criteria that represents the academic duties such as teaching, supervision, research, publication, consultation, service to university and leadership as shown in Table III.

The implementation of NS algorithm consists of two parts which is the learning process on the training dataset and the classification process to match the detector with the new candidates to determine the accuracy of NS classifier. The highest accuracy of classifier will be selected and applied to the new data for classification purposes. In the second phase, NS algorithm has been applied that involved three stages i.e. selfdata definition, detector generation and detector matching is determined by affinity measurement. The self-data was produced randomly as the candidate that will be used in the training process as the first stage of implementation. The second stage is training phase or learning (generation) and testing phase or apply to new data (detection) that follow the basic process in negative selection algorithm, as shown in Fig. 4. Fig. 5 shows the model development framework for negative selection algorithm. Sample of training and testing dataset is shown in Fig. 6.

The matching process between candidate and initial memory cell that randomly generated will be executed. This process will recognize whether the candidate is self of non-self.
Then, those candidates that match with self-data will be discard and would not be considered as detector. The detector for nonself will be used to detect and recognize anomaly or negative using matching process in detection process. The matching process is intent to know whether the new data match or not with the data in memory cell by calculate their affinity measure. The Euclidean distance function is used as affinity measurement for the matching process. This function will calculate the distance be-tween two focus points and compare with the threshold value to recognize the normal (positive) or abnormal (negative) data. This measurement method will help the process of filtering the non-self or negative cell.

TABLE. II. EXPERIMENT PHASE DESCRIPTION

\begin{tabular}{|l|l|}
\hline Phase & \multicolumn{1}{|c|}{ Description } \\
\hline Data-set & $\begin{array}{l}\text { Academic leadership dataset collected from } \\
\text { academic promotion evaluation data. }\end{array}$ \\
\hline & $\begin{array}{l}\text { Phase 1: Generation } \\
\text { •Attributes - 7 attributes } \\
\text { •Number of data }-80 \\
\text { •Method- Random generator } \\
\text { Model Development } 2: \text { Detection /Matching rule } \\
\text { •Method- Euclidean distance based for real } \\
\text { valued representation }\end{array}$ \\
\hline Model Analysis & 10-fold cross validation \\
\hline
\end{tabular}

TABLE. III. DATA DESCRIPTION

\begin{tabular}{|l|l|}
\hline Criteria & Attributes \\
\hline \multirow{3}{*}{ Demographic } & Year \\
& Gender \\
& Grade Promotion \\
\hline & Teaching and supervision \\
& Research and publication \\
Academic Leadership & Consultation and/or Expertise \\
Criteria & Conference Participation \\
& Service University/Community \\
& Academic award \\
& Leadership and personal attitude \\
\hline
\end{tabular}

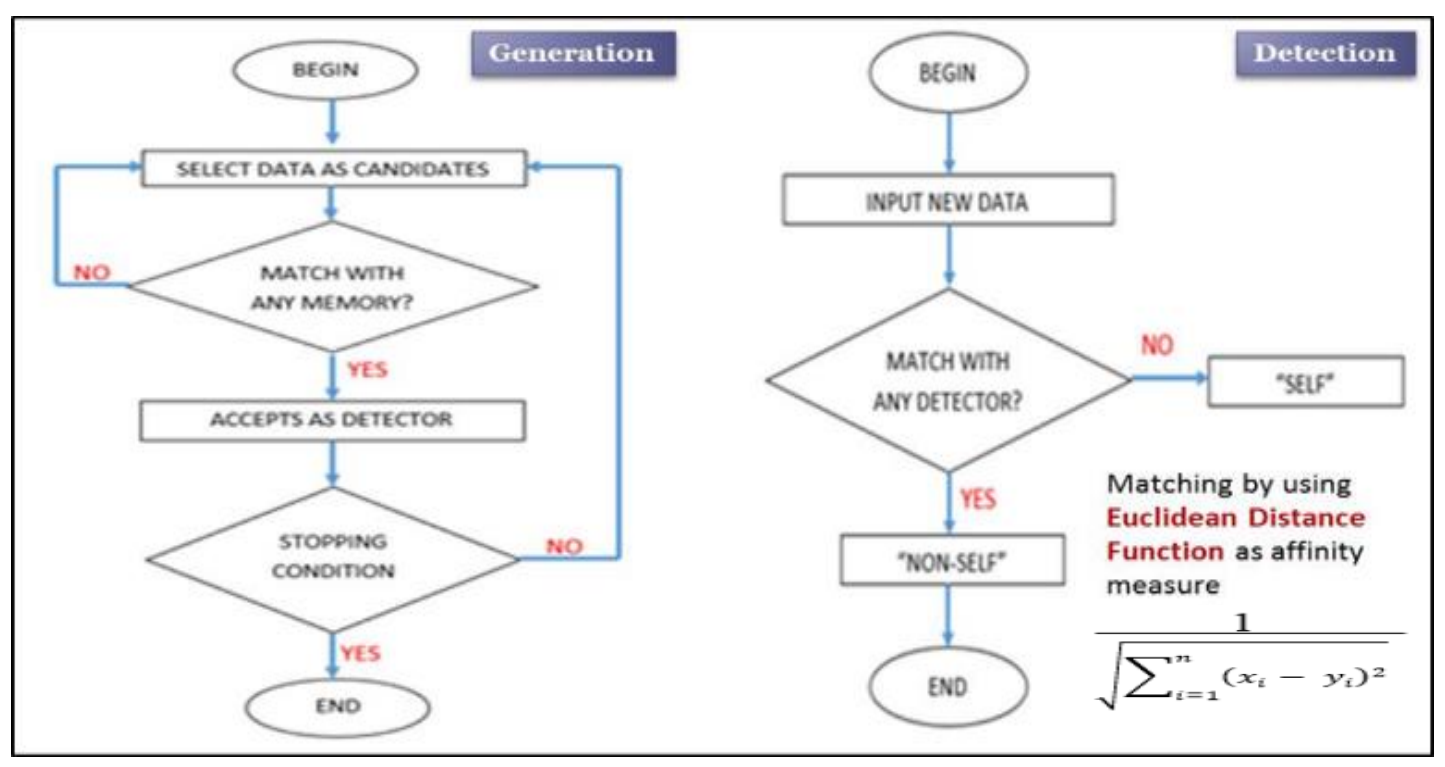

Fig. 4. Learning Process in Negative Selection Algorithm. 

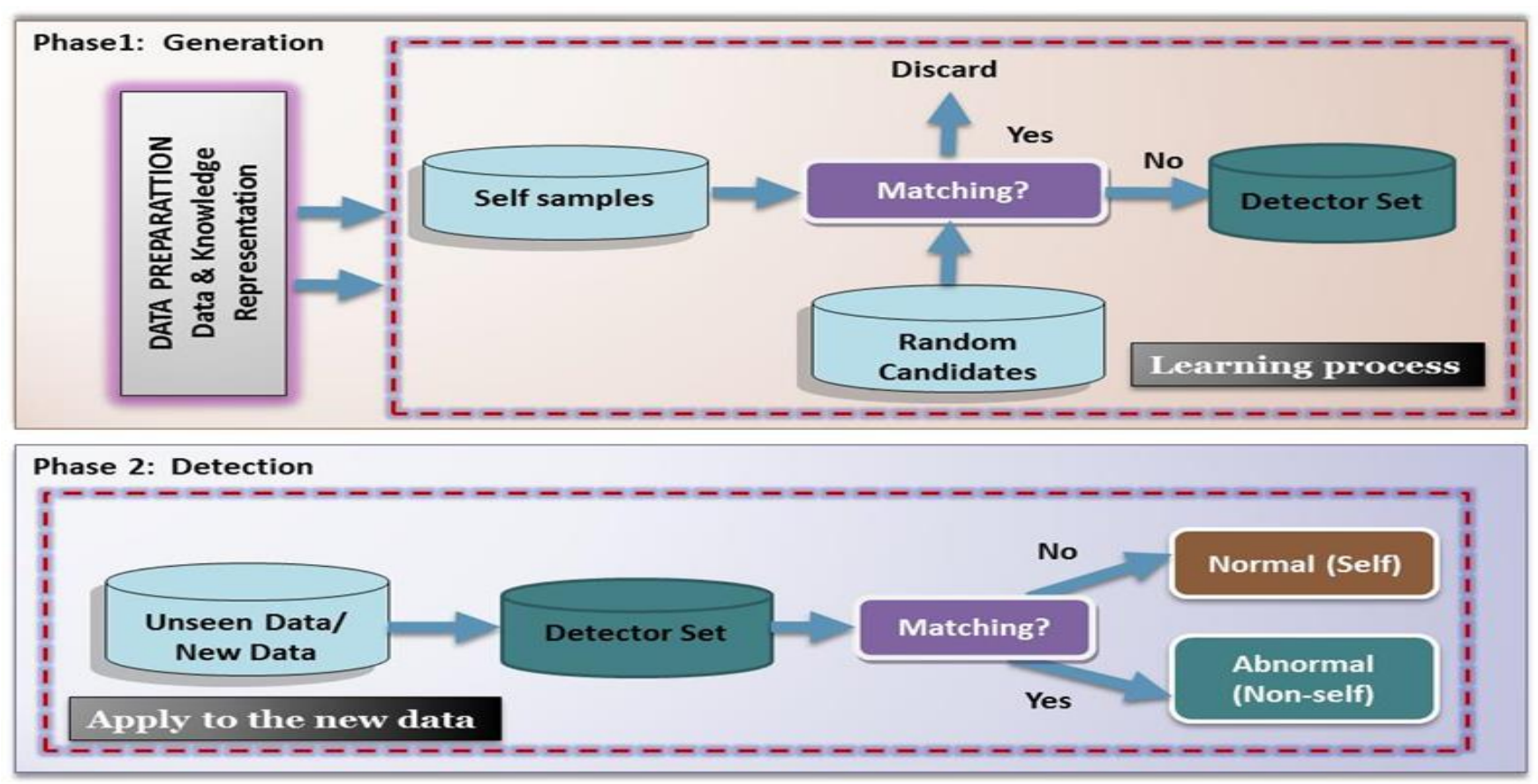

Fig. 5. Negative Selection Model Development Framework.

\begin{tabular}{|ll|}
\hline trainingData [52] & $100.00,57.33,45.00,60.00,53.00,30.00,75.00$ \\
trainingData [53] & $100.00,25.00,20.00,40.00,59.00,50.00,70.00$ \\
trainingData [54] & $100.00,20.00,50.00,28.00,55.00,70.00,95.00$ \\
trainingData [55] & $100.00,48.50,70.00,50.00,50.00,40.00,70.00$ \\
trainingData [56] & $100.00,70.00,70.00,82.00,90.00,90.00,88.00$ \\
trainingData[57] & $100.00,30.00,70.00,20.00,30.00,40.00,60.00$ \\
train1ngData [58] & $100.00,85.00,70.00,85.00,70.00,70.00,75.00$ \\
trainingData [59] & $100.00,39.98,70.00,50.00,53.00,90.00,77.00$ \\
trainingData[60] & $100.00,6.70,70.00,40.00,70.00,50.00,95.00$ \\
\hline
\end{tabular}

\begin{tabular}{|c|c|}
\hline LestinqData $[0]$ & $65.00,97.00,70.00,45.00,100.00,100.00,40.00$ \\
\hline cestinqData [1] & $100 \cdot 00,43 \cdot 50,60 \cdot 00,50 \cdot 00,50 \cdot 00,50 \cdot 00,50 \cdot 00$ \\
\hline testingData [2] & $92.50,65.00,65.00,53.00,50 \cdot 00,100.00,75.00$ \\
\hline testingData[3] & $100 \cdot 00,35.43,70 \cdot 00,40.00,86.00,90.00,100.00$ \\
\hline testingDaza [4] & $100,00,13,33,30,00,24,00,89,00,50,00,75,00$ \\
\hline testingData [5] & $100 \cdot 00,85.00,30 \cdot 00,40 \cdot 00,50 \cdot 00,50 \cdot 00,75.00$ \\
\hline testinđData [6] & $100 \cdot 00,45.00,70 \cdot 00,34 \cdot 00,70 \cdot 00,50 \cdot 00,53.00$ \\
\hline testinđData [7] & $100 \cdot 00,60.00,70 \cdot 00,40.00,80.00,100.00,77.00$ \\
\hline
\end{tabular}

Fig. 6. Sample of Training and Testing Datasets.

\section{RESUlt AND Discussion}

In this paper, the proposed negative selection classifier was developed through generation and detection processes that produce a set of detectors that are considered as non-self or negative selection classifier. Fig. 7 shows the process involved in this study that contains the generation and matching process to produce the set of detectors. The sample of negative selection detector as NS model produced in the learning proses is shown in Fig. 8. The accuracy of NS classifier was determined by 10 -fold cross validation model in learning process using selected data set as mentioned in Table IV.

The accuracy of the model determined through matching between the candidates and set of identified detectors would be classified as negative, abnormal or non-self-cell. The result shows that 90:10 and 70:30 models produced highest accuracy. Besides that, the average of accuracy for NS algorithm is $85.86 \%$ and this would be considered as good and acceptable enough for classification. In model construction phase, the accuracy of the model is very important to produce an accurate result for classification and prediction.

As an example, result from evaluation phase for evaluating the proposed NS classifier to determine the right academia in promotion exercise is shown in Fig. 9. The result shows that NS algorithm can also be considered as potential approach for academic leadership assessment.

TABLE. IV. Negative SELECTION Model ANALysis

\begin{tabular}{|l|l|l|}
\hline $\begin{array}{l}\text { 10 Fold Cross } \\
\text { Validation Model }\end{array}$ & Accuracy & Description (Average) \\
\hline $90: 10$ & 100.00 & $\uparrow$ (Potential Model) \\
\hline $80: 20$ & 66.67 & $\downarrow$ \\
\hline $70: 30$ & 100.00 & $\uparrow$ (Potential Model) \\
\hline $60: 40$ & 80.00 & $\downarrow$ \\
\hline $50: 50$ & 77.78 & $\downarrow$ \\
\hline $40: 60$ & 90.00 & $\uparrow$ (Potential Model) \\
\hline $30: 70$ & 83.33 & $\downarrow$ \\
\hline $20: 80$ & 91.67 & $\uparrow$ (Potential Model) \\
\hline $10: 90$ & 83.33 & $\downarrow$ \\
\hline
\end{tabular}




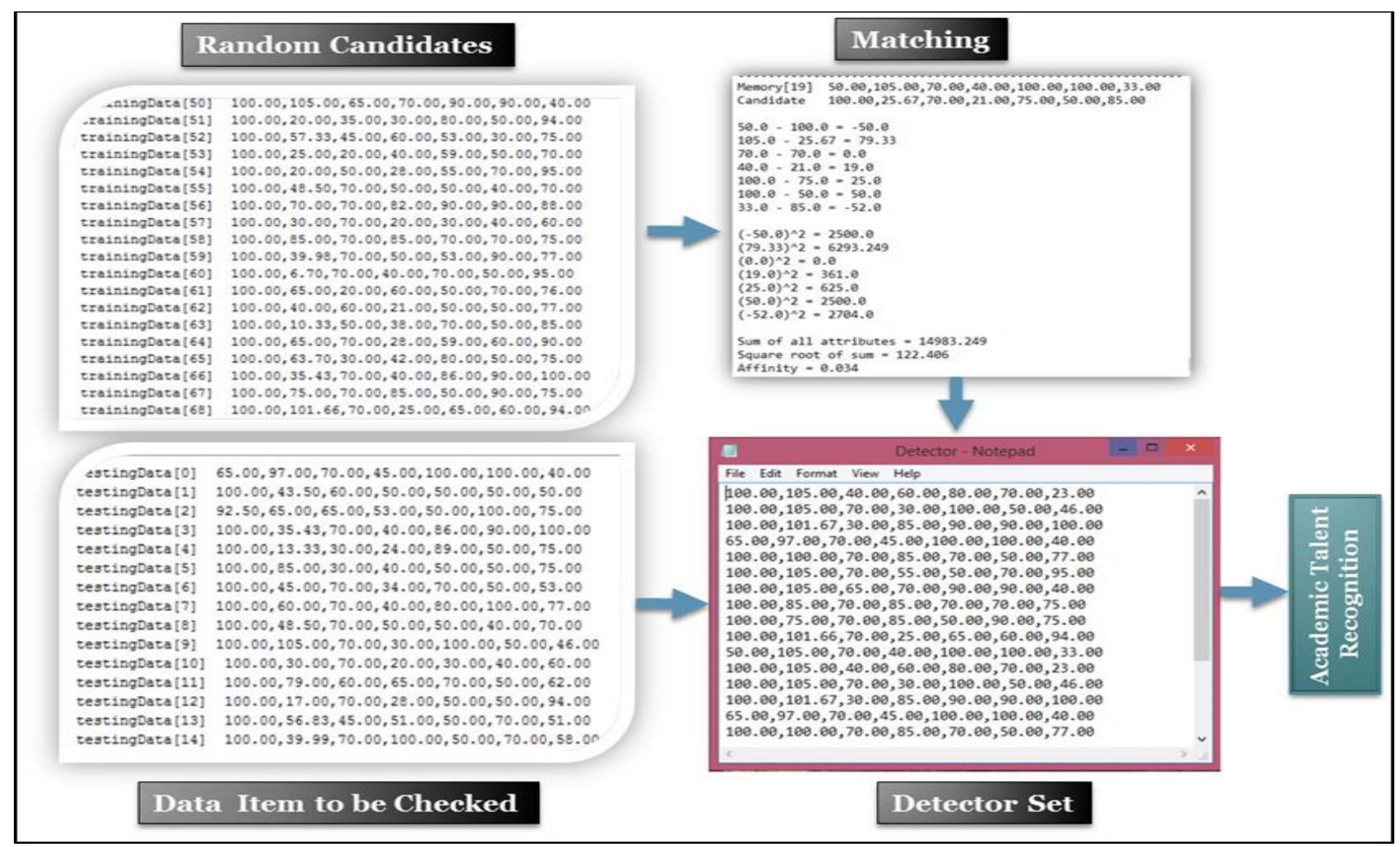

Fig. 7. Negative Selection Analysis Process.

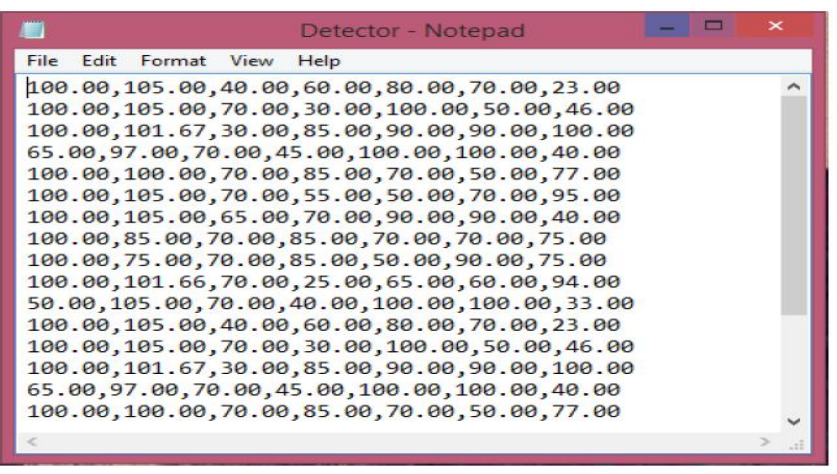

Fig. 8. Negative Selection Classifier /Detector.

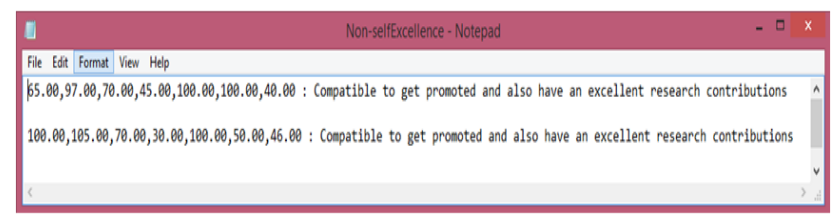

Fig. 9. Model Evaluation for Academic Leadership Assessment.

\section{CONCLUSION}

This paper proposed NS algorithm from immune-based system approach as classifier for data analysis in academic leadership assessment as a case study. However, the proposed method only focuses on research and publication datasets for assessment. In future work, the proposed method could be compared to other similar method especially for common comparison framework on other academic leadership criteria.
Besides that, there are other immune-based algorithm such as Artificial Immune Network, Clonal Selection, and Dendritic Cell algorithms need to be explored as a comparative study. It would give a new understanding in this field specially to select the most accurate result as produced by the algorithm in academic leadership assessment. Finally, this result will give a new direction of applying immune-based algorithm in human re-source activities for data analysis.

\section{ACKNOWLEDGMENT}

This research has been supported by Ministry of Education (MOE) to Universiti Tekonologi MARA (UiTM) for Fundamental Re-search Grant Scheme (FRGS) (600RMI/FRGS 5/3 (3/2016).

\section{REFERENCES}

[1] Timmis, J, Neal, M, \& Hunt, J (2000), An Artificial Immune System for Data Analysis. Biosystems, Vol. 55, No. (1-3), pp.143-150. doi: 10.1016/S0303-2647(99)00092-1.

[2] Forrest S, Perelson A S, \& Allen L. Self-nonself Discrimination in a Computer (1994), IEEE Computer Society Symposium on Research in Security and Privacy, Oakland, pp.202-212, doi: 10.1109/RISP.1994.296580.

[3] Wei Y G, Zheng D L., \& Wang Y (2004), Negative Selection Algorithm and Its Application in Anomaly Detection. Third International Conference on Machine Learning and Cybemetics, Shanghai, China, pp. 2910-2913, doi: 10.1109/ICMLC.2004.1378529.

[4] Jantan H, Hamdan A R, \& Othman Z A (2011), Data Mining Classification Techniques for Human Talent Forecasting: InTech, pp.1173-1178.

[5] Elsayed S A M, Ammar R A, \& Rajasekaran S (2012), Artificial Immune Systems: Models, Applications, and Challenges. 27th Annual ACM Symposium on Applied Computing Trento, Italy, pp.256-258. 
[6] Ji Z, \& Dasgupta D (2007), Revisiting Negative Selection Algorithms. Evolutionary Computation, Vol. 15, No. 2, pp.223-251. doi: 10.1162/evco.2007.15.2.223.

[7] Soam S S, Khan F, Bhasker B, \& Mishra B N (2011), Identification of MHC Class II binders/ non-binders using Negative Selection Algorithm. Journal of Bioinformatics and Sequence Analysis, Vol. 5, No. 2, pp.1624. doi: 10.5897/JBSA11.023.

[8] Dasgupta D, KrishnaKumar K, Wong D, \& Berry M (2004), Negative Selection Algorithm for Aircraft Fault Detection. International Conference on Artificial Immune Systems, Vol. 3239, pp.1-13, doi: 10.1007/978-3-540-30220-9_1.

[9] Lima F P A, Lotufo A D P, \& Minussi C R (2014), Disturbance Detection for Optimal Database Storage in Electrical Distribution Systems using Artificial Immune Systems with Negative Selection. Electric Power Systems Research, Vol. 109, pp.54-62. doi: 10.1016/j.epsr.2013.12.010.

[10] Idris I, \& Selamat A (2011), Negative selection algorithm in artificial immune system for spam detection. 5th Malaysian Conference in Software Engineering (MySEC), Johor Bahru, Malaysia, pp.379-382, doi: 10.1109/MySEC.2011.6140701.

[11] Taylor D W \& Corne D W (2003), An Investigation of the Negative Selection Algorithm for Fault Detection in Refrigeration Systems. International Conference on Artificial Immune Systems, Vol. 2787, pp.34-45, doi: 10.1007/978-3-540-45192-1_4.

[12] Kim J \& Bentley P J (2001), An Evaluation of Negative Selection in An Artificial Immune System for Network Intrusion Detection. Genetic and Evolutionary Computation Conference (GECCO).

[13] Hooks D, Yuan X, Roy K, Esterline \& Joaquin Hernandez J (2018), Applying Artificial Immune System for Intrusion Detection. 2018 IEEE Fourth International Conference on Big Data Computing Service and Applications (BigDataService), Bamberg, Germany, doi: 10.1109/BigDataService.2018.00051.

[14] Bendiab E \& Kholladi M K (2012), Insupervised Classification Based Negative Selection Algorithm. Courrier du Savoir, Vol. 14, pp.31-35
[15] Muda A K, Muda N A \& Choo Y H (2017), Recognizing Music Features Pattern Using Modified Negative Selection Alonrithm for Songs Genre Classification. Advances in Intelligent Systems and Computing, Vol. 734, pp.242-251.

[16] Paul S, Janecek A, Neto F B D L \& Marwala T (2013), Applying the Negative Selection Algorithm for Merger and Acquisition Target Identification. BRICS Congress on Computational Intelligence and 11th Brazilian Congress on Computational Intelligence (BRICS-CCI \& CBIC), Ipojuca, Brazil, doi: 10.1109/BRICS-CCI-CBIC.2013.107.

[17] Bölükbaş O \& Harun Uğuz H (2018), Performance of Negative Selection Algorithms in Patient Detection and Classification. NatureInspired Intelligent Techniques for Solving Biomedical Engineering Problems, Vol. 14, pp.25-31.

[18] Tariquea I \& S Schuler R (2010), Global talent management: Literature review, integrative framework, and suggestions for further research. Journal of World Business, Vol. 45, No. 2, pp.122-133. doi: 10.1016/j.jwb.2009.09.019.

[19] Ismail M \& Rasdi R M (2008), Leadership in an Academic Career: Uncovering the Experience of Women Professors. International Studies in Educational Administration (Commonwealth Council for Educational Administration \& Management (CCEAM)), Vol. 3, No. 36, pp.87-103.

[20] Vincent-Lancrin S (2006), What is Changing in Academic Research? Trends and Futures Scenarios. European Journal of Education, Vol. 41, No. 2. doi: 10.1111/j.1465-3435.2006.00255.x.

[21] Verhaegen P (2006), Academic talent: Quo vadis? Recruitment and retention of faculty in European business schools. Journal of Management Development, Vol. 24, No. 9.

[22] Chang J R, Cheng C H \& Chen L S (2007), A Fuzzy-based Military Officer Performance Appraisal System. Applied Soft Computing, Vol. 7, No. 3, pp.936-945. doi: 10.1016/j.asoc.2006.03.003.

[23] Jantan H, Hamdan A R \& Othman Z A(2009), Knowledge Discovery Techniques for Talent Forecasting in Human Resource Application. World Academy of Science, Engineering and Technology, Vol. 3, No.2, pp.775-78. 